\title{
Representative sample of rheumatoid synovium: a morphometric study
}

\author{
T D KENNEDY, C PLATER-ZYBERK, T A PARTRIDGE, * D F WOODROW, * R N MAINI \\ From the Kennedy Institute of Rheumatology and the *Department of Histopathology, Charing Cross Hospital, \\ London
}

SUMMARY The synovium from 11 patients with rheumatoid arthritis, who were undergoing joint surgery, was assessed using histological and morphometric techniques. Histological examination confirmed previous reports that the intensity of the cellular reaction varied throughout the synovium, and the morphometric method reflected this variability sensitively. The method was shown to be reproducible and allowed areas of similar cellular density to be defined. From these defined areas a total of $2.5 \mathrm{~mm}^{2}$ of synovium equivalent to 12 fields at $\times 250$ required analysis to reflect the variation in the cellular reaction.

It would be feasible to collect this amount of material using an arthroscope.

Variability in the intensity of the cellular reaction in rheumatoid synovium has been recognised for more than 50 years. ${ }^{12}$ Nevertheless, many studies have taken small biopsy specimens to be representative not only of the entire histological pattern of that synovium but also the disease state ${ }^{3-9}$ Clearly, important histological features might be missed in small samples and if advances are to be made in the understanding of the pathological process, enough tissue must be examined to allow for this expected variation..$^{10-12}$

This study aimed to assess the minimal amount of synovium requiring examination so as to reflect the variation in the cellular reaction. Once achieved, the cellular composition of representative samples of synovium could be determined and objective changes in this composition followed up to assess progression of disease or the effects of treatment.

\section{Material and methods}

Fresh synovium was obtained from 11 patients with classic or definite rheumatoid arthritis ${ }^{6}$ who were undergoing joint surgery. The synovium was collected from the operating theatre in dry sterile pots. It was described macroscopically and immediately trimmed into between three and five blocks each measuring about $1 \mathrm{~cm}^{3}$. After fixation in formalin sections $(5$ microns thick) were cut and stained with Carazzi's haematoxylin and eosin.

Accepted for publication 3 March 1988

\section{MOR PHOMETRIC TECHNIQUES}

A nearest neighbour analysis, previously applied to estimate the density of neurons, ${ }^{13}$ was used to assess the density of cells in a particular projected field (fig 1). A semiautomated image analysis system, comprising an inverted Leitz microscope which projected a tissue section on to a digitising tablet, a computer, and a receiver pen, was used to record the coordinates of the points of contact between the pen and the tablet. The computer then calculated the distance between these coordinates. The system was calibrated by projecting a 1000 micron stage micrometer slide on to the tablet and a magnification factor $(\times 467)$ was calculated. The area of the projected field using a $\times 25$ objective was $0.28 \mathrm{~mm}^{2}$. The nuclear density was calculated from the formula described in fig 1 and was expressed as area per nucleus (An) with standard error (SE An): the more usual measure of density (nuclei $\mathrm{mm}^{-2}$ ) was derived from the inverse of An. The technique assumed that the cells were randomly distributed over the sampling area and that this could be tested $\left(t_{n}\right)$ using the described statistical method (fig 1). The analysis was reproducible as no significant difference was observed between the range of densities when three observers independently assessed one of the synovia. Intraobserver error was not significant.

The cellular density of the whole biopsy specimen was assessed by calculating the mean density of randomly chosen fields. This was achieved by positioning the tissue with the surface of the synovial lining layer in view. The slide was moved randomly around the screen and whether the field contained synovial lining layer or an aggregate was recorded. 


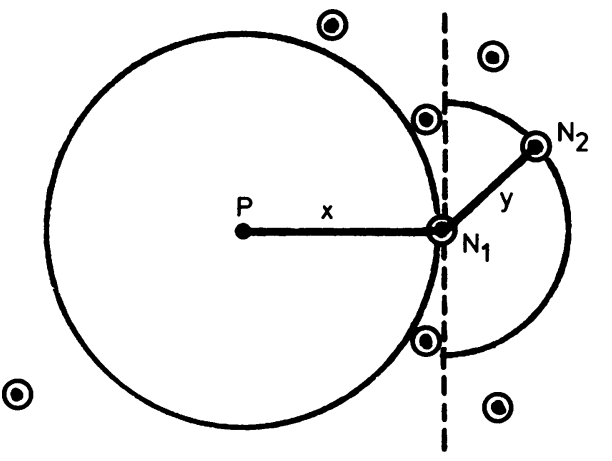

" $p$ " is a point located at random within the population at issue. The distance from " $p$ " to the nearest nucleus $N_{1}$ is drawn, measured, and denoted " $\mathrm{x}$ ". A perpendicular to PNI defines a half plane on the right of the diagram. In this half plane the distance from $N_{1}$ to its nearest neighbour $N_{2}$ is measured and denoted " $y$ ". The combined sample of $x$-distance and $y$-distances is used to estimate the mean area associated with each cell. These paired measurements $(\mathrm{x}, \mathrm{y})$ were made $10(\mathrm{n})$ times and applied to the following formulae:

$$
\begin{gathered}
\text { Area cell }{ }^{-1}(\mathrm{Ac})=\pi / 2 \mathrm{n} \sum_{i=1}^{\mathrm{n}}\left(\mathrm{xi}^{2}+\frac{1}{2} \mathrm{yi}^{2}\right) \\
\text { Standard error (SEAc) }=\mathrm{Ac} / \sqrt{ } 2 \mathrm{n} \\
\text { Cells per unit area } 1 / \mathrm{Ac}
\end{gathered}
$$

Test for random distribution of cells within test population

$$
\text { "tN" = } \Sigma \mathrm{xi}^{2} /\left(\mathrm{xi}^{2}+\mathrm{yi}^{2}\right)
$$

Significance tested using the " $z$ " transformation

$$
z=(t N-n / 2) /(\sqrt{ } n / 12)
$$

Fig 1 Calculation of nuclear density. ${ }^{13}$ (Reproduced by courtesy of the editor of the Journal of Microscopy, Blackwell Scientific Publications Limited)

Experience of this procedure led to the definition of regions (fig 2 ) based on the diameter of the projected field $(0.6 \mathrm{~mm})$ :

1 the "upper synovial region", defined as that part of the synovium within $0.6 \mathrm{~mm}$ of the surface of the synovial lining layer, including fields of view solely within villi;

2 the "lower synovial region" contained the synovium deep to $0.6 \mathrm{~mm}$ from the surface of the synovial lining layer;

3 within each of these regions were "cellular aggregates", defined as discrete collections of more than 100 predominantly mononuclear cells.

STATISTICAL ANALYSIS

The results were expressed as mean density (nuclei $\mathrm{mm}^{-2}$ ) with $95 \%$ confidence interval $(\mathrm{CI}){ }^{14}$ Student's $t$ test and Wilcoxon's rank sum test with quotient "c"15 were used to test the null hypothesis that the distribution of the calculated density of projected field between different populations was not significantly different.

As the mean nuclear density was used to describe the overall cellular reactions (XR), the representative sample was defined as the minimal number of fields whose mean density (XN) would reflect the overall density to within a per cent mean difference of $10 \%$. Although $\pm 10 \%$ accuracy is an arbitrary figure, it reflected the per cent mean difference of the $95 \%$ CI from the whole sample. The following formula was used to assess the per cent mean difference:

$$
\text { per cent mean difference }=\frac{\mathrm{XN}-\mathrm{XR}}{\mathrm{XR}} \times 100
$$

where,

$\mathrm{XN}=$ cumulative mean density of an increasing number of field " $n$ "

$\mathrm{XR}=$ overall mean of reference sample

The overall (XR) of the whole synovium or upper and lower synovial region and cellular aggregates was calculated for the accumulated data. This was compared, using the above formula, with the XN of an increasing number of randomly chosen fields (two, three . . . 15 fields) from the same sample. This analysis was performed on 10 sets of data and the mean $\pm 95 \%$ $\mathrm{CI}$ for each field number calculated (table 1). The

\begin{tabular}{|c|c|c|c|c|}
\hline \multirow[b]{2}{*}{$\begin{array}{l}\text { Number } \\
\text { of fields }\end{array}$} & \multirow[b]{2}{*}{$\begin{array}{l}\text { Whole } \\
\text { synovium }\end{array}$} & \multicolumn{2}{|c|}{ Percentage value } & \multirow[b]{2}{*}{$\begin{array}{l}\text { Cellular } \\
\text { aggregate }\end{array}$} \\
\hline & & $\begin{array}{l}\leftarrow \text { Syno } \\
\text { Upper }\end{array}$ & $\begin{array}{l}\text { al region } \rightarrow \\
\text { Lower }\end{array}$ & \\
\hline 1 & 57 & 35 & 40 & 27 \\
\hline 2 & 33 & 22 & 22 & 20 \\
\hline 3 & 33 & 20 & 19 & 11 \\
\hline 4 & 28 & 13 & 17 & $* 9$ \\
\hline 5 & 24 & 13 & 24 & 9 \\
\hline 6 & 22 & 13 & 20 & 9 \\
\hline 7 & 26 & 11 & 19 & 9 \\
\hline 8 & 22 & $* 9$ & 18 & 7 \\
\hline 9 & 20 & 9 & 18 & 9 \\
\hline 10 & 17 & 7 & 18 & 7 \\
\hline 11 & 20 & 7 & 17 & 7 \\
\hline 12 & 20 & 7 & 17 & 4 \\
\hline 13 & 22 & 7 & 16 & 4 \\
\hline 14 & 20 & 7 & 18 & 4 \\
\hline 15 & 20 & 7 & 19 & 4 \\
\hline
\end{tabular}
number of fields required to reduce the $95 \% \mathrm{CI}$ to less than $10 \%$ was used to define the size of the representative sample.

Table 1 Number of fields required for representative sampling to within $\pm 10 \%$ accuracy 


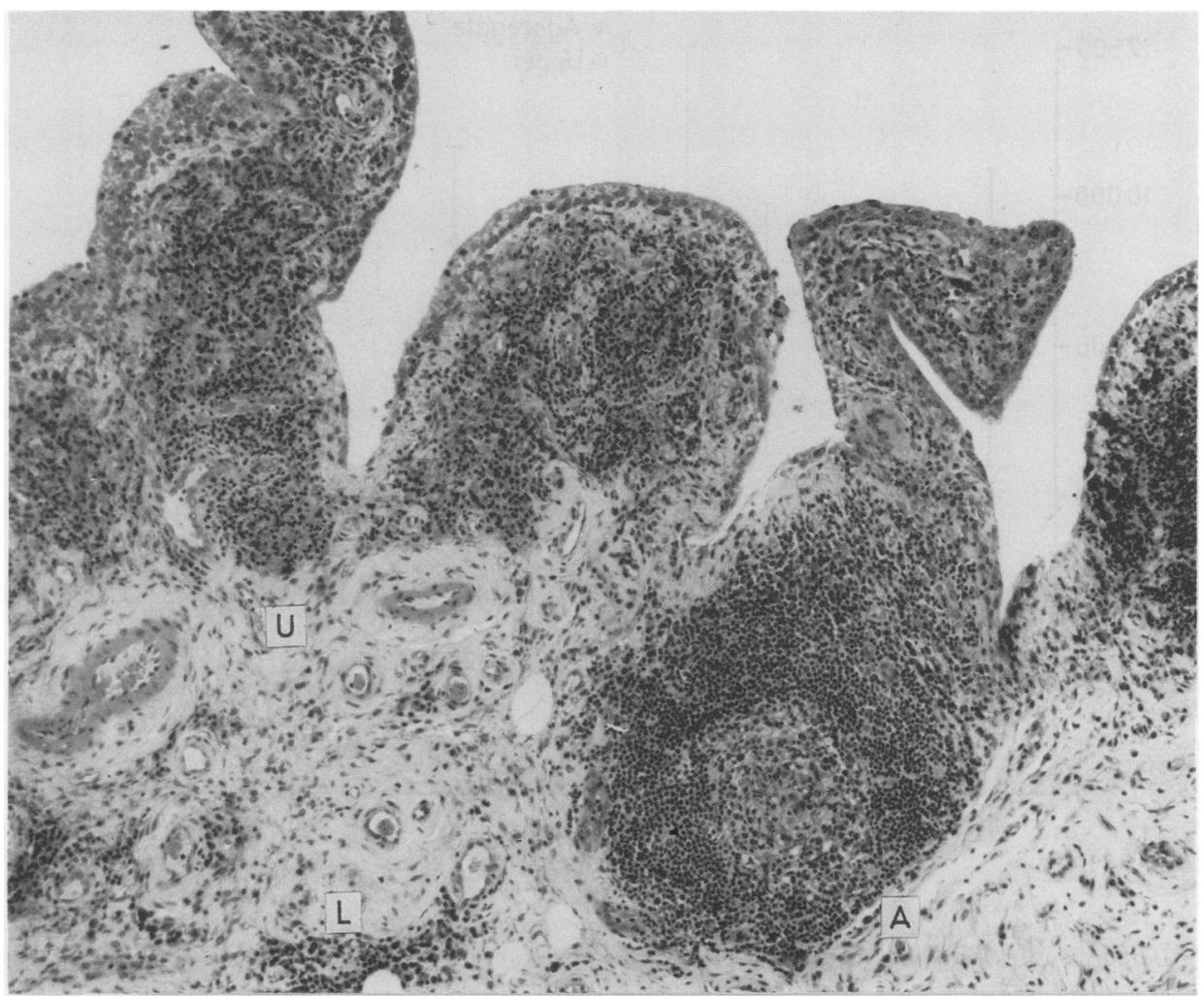

Fig 2 Definition of regions: histological section of synovium showing upper $(U)$ and lower $(L)$ synovial regions and cellular aggregates $(A)$. (Haematoxylin and eosin.)

\section{Results}

\section{HISTOLOGICAL DESCRIPTION}

The appearance of the rheumatoid synovium when examined by light microscopy confirmed previous descriptions of sections fixed in formalin and stained with haematoxylin and eosin..$^{16-18}$ It featured villus formation with hyperplasia of the synovial lining cells and a surface coating of fibrin. The area close to the synovial lining layer was highly vascular and contained an intense cellular reaction comprising lymphocytes, plasma cells, and macrophages. In some areas discrete collections of cells or "aggregates" composed of predominantly mononuclear cells were present. These were of three types. The most common were perivascular, where a collection of mononuclear cells surrounded a clearly visible blood vessel. In the second type no clearly defined blood vessel was seen and these aggregates were often surrounded by a corona of plasma cells. The third type of lymphocyte aggregate was only rarely found (three of 11 synovia) and was characterised by a paler staining centre similar to the lymphoid follicle of the lymph node. The synovial stroma was composed of collagen fibres interspersed with histiocytes, macrophages, lymphocytes and plasma cells.

\section{MOR PHOMETRIC ANALYSIS}

Using the techniques described, the nuclear density of 213 projected fields of rheumatoid synovium was calculated. Randomness of the cellular distribution was shown to a degree tolerated by the method in the whole synovium as well as the aggregate region (table 2).

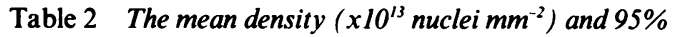
confidence interval (CI) of accumulated fields from synovium and each region

\begin{tabular}{lcccc}
\hline & $\begin{array}{c}\text { Whole } \\
\text { synovium }\end{array}$ & $\begin{array}{c}\leftarrow \text { Synovial region } \rightarrow \\
\text { Upper }\end{array}$ & $\begin{array}{l}\text { Cellular } \\
\text { Lower }\end{array}$ & aggregates \\
\hline Mean & $5 \cdot 5$ & $3 \cdot 8$ & $1 \cdot 6$ & $9 \cdot 3$ \\
$95 \%$ CI & $5 \cdot 0-6.02$ & $3 \cdot 5-4 \cdot 1$ & $1.4-1 \cdot 8$ & $9 \cdot 2-9.4$ \\
Number of fields & 213 & 94 & 44 & 75 \\
Randomness "z" & 0.99 & 0.97 & 0.59 & $1 \cdot 24$ \\
p value & 0.32 & 0.33 & 0.56 & 0.21 \\
\hline
\end{tabular}




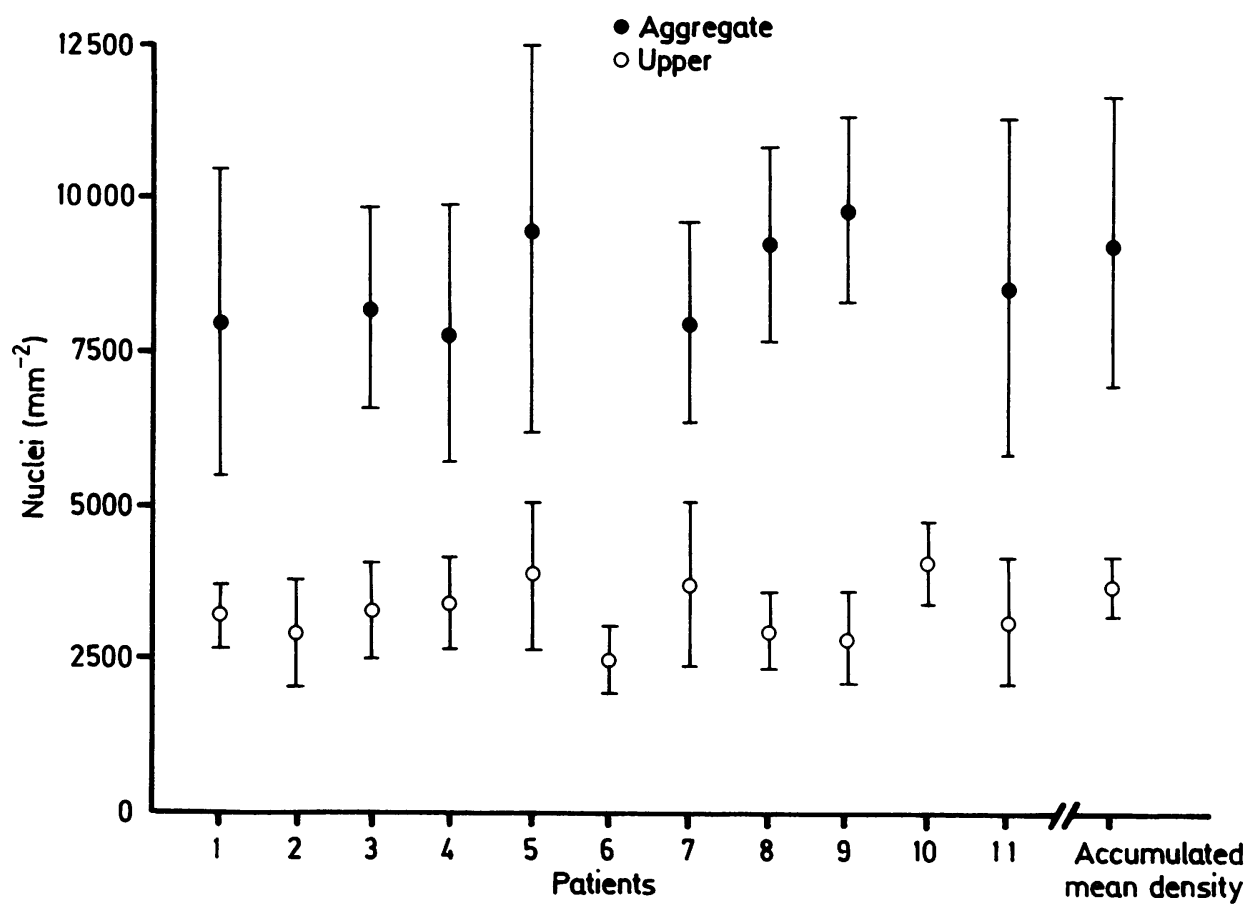

Fig 3 Representative sample of rheumatoid synovium: mean nuclear density $\left(x 10^{3}\right.$ nuclei $\left.\mathrm{mm}^{-2}\right)$ and $95 \%$ CI of accumulated and individual representative samples of upper synovial region and cellular aggregates in rheumatoid synovium.

The mean difference and $95 \% \mathrm{CI}$ for the whole sample and each region was calculated from the accumulated data (table 2). Each region was characterised by a significantly different mean density $(p<0.001)$. The number of fields required for representative sampling of each region was calculated: despite examining 15 fields, it was not possible to attain $\pm 10 \%$ sampling accuracy for the whole synovium (table 1). For the upper synovial region, however, an analysis of eight fields would provide a sample which would reflect to within a mean difference of $\pm 10 \%$, the mean density of the accumulated overall sample of 94 fields (table 1). Similarly, four aggregate fields would be representative of the mean density of the. accumulated aggregate sample of 86 fields. A representative sample of the lower region could not be defined in less than 15 fields. Therefore, to define a representative sample of defined regions within synovium, eight upper and four aggregate fields required assessment. As the area of each upper region field at this magnification was $0.28 \mathrm{~mm}^{2}$ and the mean area of 25 randomly chosen aggregates was $0.07 \mathrm{~mm}^{2}$, the total area requiring examination to define a representative sample was $2.5 \mathrm{~mm}^{2}$.

Having defined a representative sample, these criteria were then applied to the individual synovia. Each of the individual upper regions could be studied but it was only possible to assess eight synovia for aggregates. The mean nuclear density and $95 \% \mathrm{CI}$ of representative sample of individual upper and aggregate regions are shown in fig 3 . As shown there was no significant difference between synovia within the upper region except for case 6 which differed significantly from case $10(p<0.001)$ and also from the overall mean $(p<0.02)$.

\section{Discussion}

The rheumatoid synovium does not usually show histological features which are specific for the disease, the exception being occasional rheumatoid nodules ${ }^{18}$ which were not present in these specimens. The variation in the inflammatory reaction seen in rheumatoid synovitis is well recognised ${ }^{10-12}$ but few studies report the amount of tissue assessed..$^{201}$ Most findings of studies seem to be based on small amounts of tissue which are assumed to be representative not only of the total tissue but also the disease itself, such that conclusions about pathogenesis have been made. ${ }^{7-9}$ Although some studies have shown a correla- 
tion between the synovial pathology and the degree of joint activity, ${ }^{3411}$ others have shown considerable variation between different areas of the biopsy specimen. ${ }^{22}$ This study is the first to estimate the minimum amount of tissue requiring analysis to reflect the variability in the cellular reaction and so define a representative sample.

The morphometric method used had been previously applied to the estimation of neuronal density. ${ }^{1314}$ It was shown to reflect the varibility in the distribution of cells within the synovium. There are several advantages to this system. Firstly, large areas of tissue can be assessed quickly and reproducibly; with practice it took about 30 seconds to measure the 20 distances required to estimate the nuclear density of one field. Secondly, the analysis does not require the perimeter of the area under test to be known, provided the random points and their nearest neighbours fall within the test area. Experience showed that a planned approach to the estimation of cellularity produced the most reproducible results. The starting point for the analysis, the junction between the synovial lining layer and the joint cavity, was used, as this feature was readily identified and the division of the synovium into regions forced the observer to assess most of the synovium. Although a statistical approach has been adopted in earlier studies, ${ }^{23}{ }^{24}$ it was necessary to identify histological features, and these may introduce considerable bias and inconsistencies between observers. ${ }^{25}$ The present method reduced these problems so that interobserver and intraobserver errors were shown not to be significant.

Although representative sampling of the upper synovial region and cellular aggregates only was possible, it is these areas which contain the most intense cellular reaction and which can be biopsied reliably at arthroscopy. It should not be assumed, however, that if aggregates were not found in the biopsy specimen, they would be absent from the whole joint. The approximate size of each biopsy specimen collected at arthroscopy may be between 5 and $8 \mathrm{~mm}^{3}$ and as many as 12 can be taken at a time." 11 Allowing for shrinkage during histological processing, it would be expected that a representative sample of synovium would be obtained from between three and five biopsy specimens obtained under direct vision at arthroscopy. Although a percutaneous needle biopsy technique has been recommended, ${ }^{26}$ these specimens may contain only fibrin clot or fat. ${ }^{27}$

Similarity in the density of the cellular reaction within the upper and aggregate regions was shown in individual synovial regions. The mean density of only two synovia differed significantly, and no clear differences in the clinical disease activity, biopsy site, or treatment between these two patients could be identified. These biopsy specimens were all taken at the time of joint replacement surgery and so represent late stage disease. Nevertheless, as the morphometric data were accumulated from several synovia they are likely to reflect the whole pattern of the disease seen in these cases.

The importance of this study is that having defined the size of a representative sample in terms of cellularity, the composition of such tissue can then be determined. Changes in cellular composition between synovia hve been recently described as a result of drug treatment, ${ }^{2628}$ but the results could be explained by non-representative sampling. Clearly, the objective evaluation of changes in the cellular composition is important not only in assessing drug treatment but also in analysing the progression of disease.

This study has shown that quantitation of the synovium is possible and reproducible. The method was sensitive in that it reflected the variability of the cellular reaction and differences in the synovial cellularity between patients with the same clinical disease. Arthroscopy would permit biopsy of sufficient material to allow further morphometric studies on patients with well characterised disease. Changes in the grades of severity of inflammatory cell infiltrate can now be assessed on a more objective basis ${ }^{19}$ and the composition of the synovium as defined by monoclonal antibodies can be studied using these techniques. This would permit a more rational approach to the understanding of the immunoregulation within the synovium.

We express our thanks to Dr K MacRae for statistical advice, Dr B Fromson for creating the computer program to calculate the nuclear density, and to Mrs G Miller and Mrs P Porter for their technical assistance with this study.

\section{References}

1 Allison NA, Ghormley RK. In: Diagnosis in joint disease. New York: William Wood \& Company, 1931:134.

2 Parker F, Keefer CS. Gross and histologic changes in knee joint in rheumatoid arthritis. Archives of Pathology 1935;20:507-22.

3. Muirden KD, Mills KW. Do lymphocytes protect the rheumatoid joint? Br Med J 1971;4:219-21.

4 Yates DB, Scott JT. Rheumatoid synovitis and joint disease: relationship between arthroscopic and histological changes. Ann Rheum Dis 1975;34:1-6.

5 Jayson MIV, Dixon ASJ. Arthroscopy of the knee in rheumatic diseases. Ann Rheum Dis 1986;27:503-11.

6 Ropes MW, Bennett GA, Cobb S, Jacox R, Jesser RA. 1958 revision of diagnostic criteria for rheumatoid arthritis. Bull Rheum Dis 1958;9:175-6.

7 Janossy G, Panayi G, Duke O, Bofill M, Poulter LW, Goldstein G. Rheumatoid arthritis: a disease of T-lymphocyte/macrophage immunoregulation. Lancet 1981;ii:839-42.

8 Ziff M. Immunopathogenesis of rheumatoid arthritis. European Journal of Rheumatology and Inflammation 1982;5/4:469-77.

9 Zvaifler NJ. Immunopathology of inflammatory diseases: rheumatoid arthritis as an example. Adv Inflamm Res 1984;7: 1-11. 
10 Cruickshank B. Interpretation of multiple biopsies of synovial issue in rheumatic diseases. Ann Rheum Dis 1952;11:137-45.

11 Linblad S, Hedfors E. Intraarticular variation in synovitis. Arthritis Rheum 1985;28:977-86.

12 Hutton CW, Hinton C, Dieppe PA. Intra-articular variation of synovial changes in knee arthritis: biopsy study comparing changes in patellofemoral synovium and the medial tibiofemoral synovium. Br J Rhem 1987;1:5-9.

13 Aherne WA, Diggle PJ. The estimation of neuronal population density by a robust distance method. J Microscopy 1978; 114:285-93.

14 Gardner MJ, Altman DG. Confidence intervals rather than P values: estimation rather than hypothesis testing. $\mathrm{Br} M e d \mathrm{~J}$ 1986;292;:746-50.

15 Geigy Pharmaceuticals. Scientific tables. In: Statistical Methods Macclesfield: Geigy Pharmaceutical, 1975:146-96.

16 Soren A. Histodiagnosis and clinical correlation of rheumatoid and other synovitis. Stuttgart: George Theime, 1978:172.

17 Gardner DL. Pathology of the connective tissues. London: Edward Arnold Publishers Ltd, 1965:68-87.

18 Vernon-Roberts B. Rheumatoid joint pathology re-visited. Recent advances in rheumatology 1985:73-95.

19 Meijer CJLM, deGraaff-Reitsma CB, Lafeber GJM, Cats A. In situ localisation of lymphocyte subsets in synovial membranes of patients with rheumatoid arthritis with monoclonal antibodies. $J$ Rheumatol 1982;9:359-65.

20 Johnell $O$, Hulth A, Henricson A. T-lymphocyte subsets and HLA-DR expressing cells in the osteoarthritic synovialis. Scand $J$ Rheumatol 1982;14:259-64.
21 Henderson DRF, Jayson MIV, Tribe CR. Lack of correlation of synovial histology with joint damage in rheumatoid arthritis. Ann Rheum Dis 1975;34:7-11.

22 Cooper NS, Soren A, McEwen C, Rosenberger JL. Diagnostic specificity of synovial lesions. Hum Pathol 1981;12:314-28.

23 Rosenberger JL, Cooper NS, Soren A, McEwen C. A statistical approach to the histopathological diagnosis of synovitis. Hum Pathol 1981;12:329-37.

24 Vernon-Roberts B. Synovial pathophysiology-diagnostic features and their standardisation. $N Z J$ Med 1978;8(Suppl 1):16-19.

25 Walters MT, Smith JL, Moore K, Evans PR, Cawley MID. An investigation of disease modifying antirheumatic drugs on the rheumatoid synovial membrane: reduction in $\mathrm{T}$ lymphocyte subpopulations and HLS-DP and DQ antigen expression after gold or penicillamine therapy. Ann Rheum Dis 1987;46:7-16.

26 Gibson T, Fagg N, Highton J, Wilton M, Dyson M. The diagnostic value of synovial biopsy in patients with arthritis of unknown cause. Br J Rheum 1985;24:232-41.

27 Rooney M, Condell D, Whelan A, Feighery C, Bresnihan B. Lymphocyte infiltration of the synovial membrane is substantially impaired following remission induced by gold salts in rhematoid arthritis Br J Rheum 1986;25:80.

Requests for reprints to: Dr T D Kennedy, Department of Rheumatology, Arrowe Park Hospital, Upton, Wirral, Merseyside L49 5PE, England. 